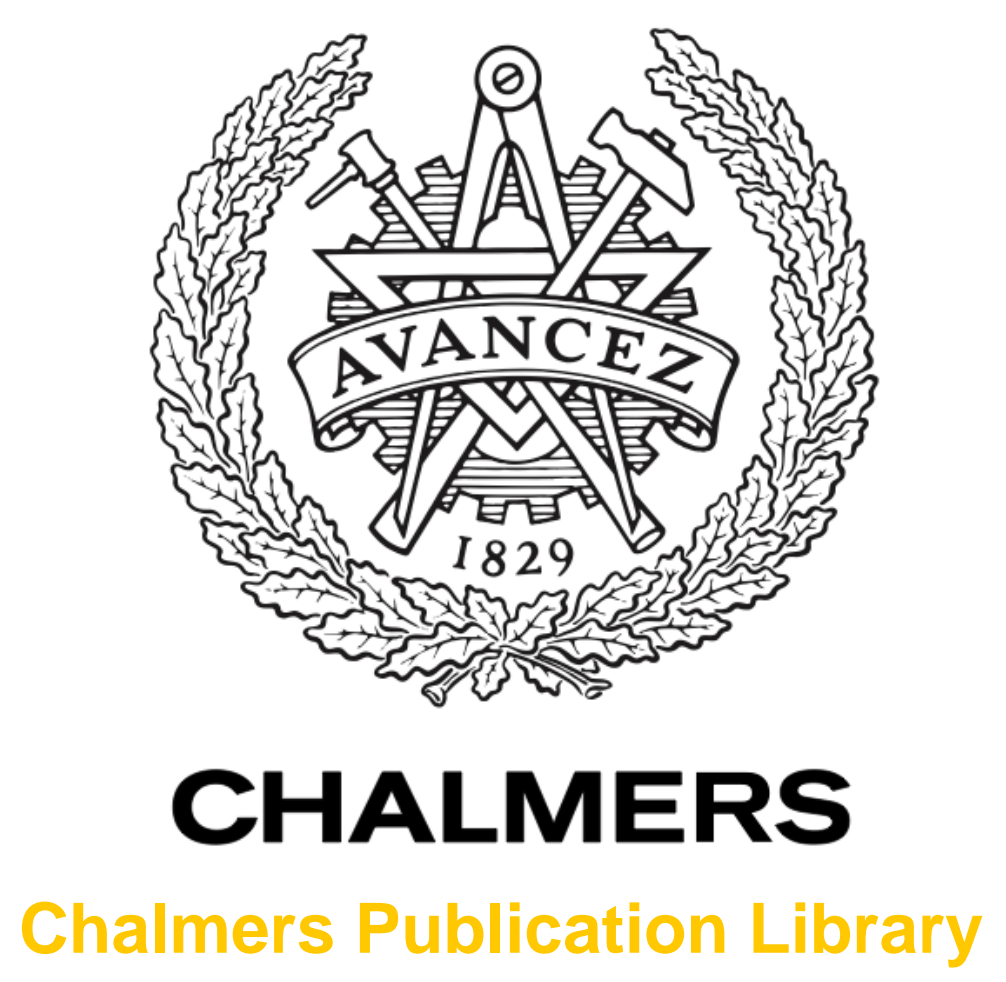

\title{
Measurements and modelling of three- and five-limb transformer behaviour during large voltage and frequency disturbances
}

This document has been downloaded from Chalmers Publication Library (CPL). It is the author's version of a work that was accepted for publication in:

IET Generation, Transmission \& Distribution (ISSN: 1751-8687)

Citation for the published paper:

Persson, M. ; Baig, W. ; Thiringer, T. (2015) "Measurements and modelling of three- and five-limb transformer behaviour during large voltage and frequency disturbances". IET

Generation, Transmission \& Distribution

Downloaded from: http://publications.lib.chalmers.se/publication/225282

Notice: Changes introduced as a result of publishing processes such as copy-editing and formatting may not be reflected in this document. For a definitive version of this work, please refer to the published source. Please note that access to the published version might require a subscription. 


\title{
Measurements and modelling of three- and five-limb transformer behaviour during large voltage and frequency disturbances
}

ISSN 1751-8687

Received on 10th February 2015 Revised on 23rd September 2015 Accepted on 6th October 2015 doi: 10.1049/iet-gtd.2015.0194 www.ietdl.org

\author{
Mattias Persson $\bowtie$, Waqas Baig, Torbjörn Thiringer \\ Division of Electric Power Engineering, Chalmers University of Technology, Gothenburg 41296, Sweden \\ $\bowtie$ E-mail: mattias.persson@chalmers.se
}

\begin{abstract}
This study presents the modelling of transformers for voltage disturbances. The focus in this study is on the security of the power supply for sensitive loads, for instance, the auxiliary systems for a nuclear power station feeding, for instance, pumps for emergency systems. Both steady-state operation as well as transient conditions have been analysed. A five-limb as well as a three-limb $4 \mathrm{kVA}$ transformer was designed in order to verify theoretical assumptions with experimental results. The results show that the theoretical models provided results in conformity to the actual experiments with an average discrepancy of $3 \%$. Moreover, it is shown that a five-limb transformer gives lower inrush currents, especially in the highly saturated region. In addition, it was demonstrated that an inductive load gives much higher inrush currents compared with a resistive load. A final observation was that the current drawn by the two transformers in their saturated state differ severely depending on the topology of the core.
\end{abstract}

\section{Introduction}

It is of extreme importance to avoid tripping of a nuclear power plant unless it is really necessary. To ensure continued operation during a network fault, or if needed, to perform a proper shut-down with minimum stress on the system, it is vital that the auxiliary supply for, among other loads, the emergency system is maintained at a sufficient quality. One of the key elements in this is the transformers and their behaviour [1].

A lot of research has been performed related to the modelling and simulation of transformers. If there is a need for handling high-frequency components, models presented in [2-4] can be used. The behaviour of transformers related to their zero sequence impedance for three-limb and five-limb topology has been studied in [5-7]. Various voltage profiles using different models have been implemented in simulation software $[8,9]$, but there is a lack of comparison to practice [10]. Missing is, however, a simple but adequate model along with laboratory tests that will result in a good basis for comparison between the two topologies. It will be interesting to make models of the two transformer types and validate them by experimentation.

The purpose of this paper is to present a simple but yet accurate model for three- and five-limb transformers as well as to evaluate and compare their static and dynamic behaviour. Furthermore, a goal is to use test cases extracted from real scenarios related to voltage and frequency levels in an auxiliary power system, and see the resulting current and voltage behaviour.

\section{Theoretical modelling and test setup}

2.1 Reluctance differences between three- and five-limb transformers

The aim of this subsection is to discuss the differences in reluctance between the two types of transformers and their different behaviour during unbalanced conditions. A simplified reluctance model of a five-limb three-phase transformer can be seen in Fig. 1.

Where $R_{\text {limb }}$ is the reluctance of the outer limbs of the transformer and $R$ is the reluctance of the different phase legs, which is here assumed equal for simplicity reasons. $\phi_{1}$ is the flux induced in the first phase leg due to the turns $N$ and the current $i_{1}$. Similarly for the other phases. $\phi_{\text {limb }}$ is the flux in the outer path which for the three limb could be assumed to be equal to zero.

Expressing the magnetic flux in phase leg $1, \phi_{1}$, by using super position $\left(\phi_{1}=\phi_{11}+\phi_{21}+\phi_{31}\right)$ results in

$$
\begin{aligned}
\Phi_{11} & =\frac{N i_{1}}{R+\left(\left(\left(R_{\mathrm{limb}} R / 2\right)\right) /\left(\left(R_{\mathrm{limb}} / 2\right)+(R / 2)\right)\right)} \\
& =\frac{N i_{1} 2\left(R_{\mathrm{limb}}+R\right)}{R\left(3 R_{\mathrm{limb}}+2 R\right)}
\end{aligned}
$$

$$
\begin{aligned}
\Phi_{21}=- & \frac{N i_{2}}{R+\left(\left(\left(R_{\text {limb }} R / 2\right)\right) /\left(\left(R_{\text {limb }} / 2\right)+(R / 2)\right)\right)} \\
& \frac{\left(\left(R_{\text {limb }} R / 2\right) /\left(R+R_{\text {limb }} / 2\right)\right)}{R+\left(\left(R_{\text {limb }} R / 2\right) /\left(R+R_{\text {limb }} / 2\right)\right)}=-\frac{N i_{2} R_{\text {limb }}}{R\left(3 R_{\text {limb }}+2 R\right)}
\end{aligned}
$$

In a similar way as (2), $\Phi_{31}$ can be expressed as

$$
\Phi_{31}=-\frac{N i_{3} R_{\text {limb }}}{R\left(3 R_{\text {limb }}+2 R\right)}
$$

resulting in a $\Phi_{1}$ equal to

$$
\Phi_{1}=\frac{2 N i_{1}\left(R+R_{\text {limb }}\right)}{3 R R_{\text {limb }}+2 R^{2}}-\frac{N\left(i_{2}+i_{3}\right) R_{\text {limb }}}{R\left(3 R_{\text {limb }}+2 R\right)}
$$

As a verification, $R_{\text {limb }}$ can be assumed to be infinity resulting in the expression of the magnetic flux in the first phase leg of a three phase three-limb transformer, which can be derived in a similar way but removing $R_{\text {limb }}$ from Fig. 1

$$
\Phi_{1(\text { three-limb) }}=\frac{2 N i_{1}}{3 R}-\frac{N\left(i_{2}+i_{3}\right)}{3 R}
$$

The five-limb transformers outer limbs produce a low reluctance path for flux during unbalanced conditions such as during saturation of the transformers. For the three-limb transformer unbalanced flux must travel from top yoke to the bottom yoke through the air further drawing current during stressed conditions [11]. These events cause high flux (proportional to $V / f$ ), resulting in larger 


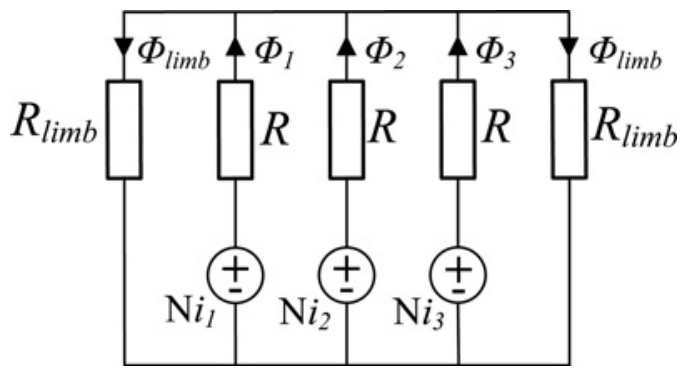

Fig. 1 Simplified reluctance model of a five-limb transformer

reactive power consumption [12] of transformers subjected to these imbalances.

\subsection{Transformer modelling}

The model used is a two-axis $d q$-model [13]. The model was made non-rotating and the parameters were extracted from two down scaled, $4 \mathrm{kVA}$, three- and five-limb transformers specially ordered with similar specifications to enable a comparison of the results. The ordered transformers were also designed with a $40 \%$ increased copper area in the windings to ensure a more comparative $R / X$-ratio to the ones found in larger transformers, as well as the possibility to easily magnetically overload/underload the transformers. For more information see [13].

On the basis of the fifth-order park model which is also referred to as the two-axis model, the primary $u_{\mathrm{p}}$ and secondary $u_{\mathrm{s}}$ voltage is obtained by

$$
\begin{aligned}
& u_{\mathrm{p}}=i_{\mathrm{p}} R_{\mathrm{p}}+\frac{\mathrm{d}}{\mathrm{d} t} \psi_{\mathrm{p}}+\mathrm{j} \omega_{k} \psi_{\mathrm{p}} \\
& u_{\mathrm{s}}=i_{\mathrm{s}} R_{\mathrm{s}}+\frac{\mathrm{d}}{\mathrm{d} t} \psi_{\mathrm{s}}+\mathrm{j} \omega_{k} \psi_{\mathrm{s}}
\end{aligned}
$$

where subscript $\mathrm{p}$ and $\mathrm{s}$ denotes the primary and secondary quantities, respectively, $i_{\mathrm{p}}$ and $i_{\mathrm{s}}$ are the primary and secondary currents, $R_{\mathrm{p}}$ and $R_{\mathrm{S}}$ are the resistances of the primary and secondary windings, respectively, $\psi_{\mathrm{p}}$ and $\psi_{\mathrm{s}}$ are the flux linkages of the primary and secondary side and $\omega_{k}$ denotes the angular speed of the coordinate system. The model is implemented in the $\alpha \beta$-coordinated system, thus $\omega_{k}=0$. The flux linkage $\psi_{\mathrm{p}}$ and $\psi_{\mathrm{s}}$ are obtained through the following equation

$$
\begin{gathered}
\psi_{\mathrm{p}}=L_{\mathrm{p}} i_{\mathrm{p}}+L_{\mathrm{m}} i_{\mathrm{s}}=\left(L_{\mathrm{p} \lambda}+L_{\mathrm{m}}\right) i_{\mathrm{p}}+L_{\mathrm{m}} i_{\mathrm{s}} \\
\psi_{\mathrm{s}}=L_{\mathrm{m}} i_{\mathrm{p}}+L_{\mathrm{s}} i_{\mathrm{s}}=\left(L_{\mathrm{s} \lambda}+L_{\mathrm{m}}\right) i_{\mathrm{s}}+L_{\mathrm{m}} i_{\mathrm{p}}
\end{gathered}
$$

where $L_{\mathrm{p}}$ and $L_{\mathrm{s}}$ are the secondary and primary inductances of the series branches, $L_{\mathrm{m}}$ is the magnetising inductance while $L_{\mathrm{p} \lambda}$ and $L_{\mathrm{s} \lambda}$ are the leakage inductances of the primary and secondary windings, respectively. The equivalent circuit for the model parameters are shown in Fig. 2.

Equations (6)-(9) can be written in matrix form as

$$
\boldsymbol{U}=\boldsymbol{R} \boldsymbol{I}+\boldsymbol{L} \frac{\mathrm{d}}{\mathrm{d} t} \boldsymbol{I}
$$

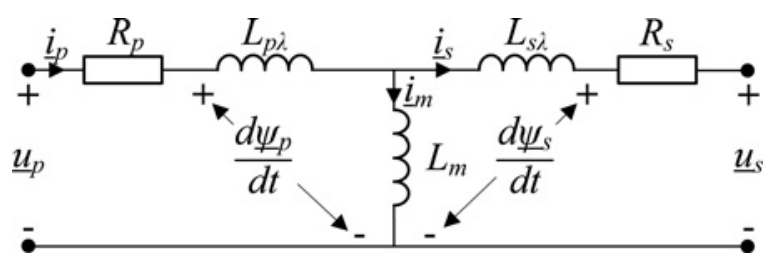

Fig. 2 Transformer equivalent circuit where $\boldsymbol{U}$ is the voltage vector, $\boldsymbol{I}$ the current vector, $\boldsymbol{R}$ the resistance matrix and $\boldsymbol{L}$ the inductance matrix

$$
\begin{gathered}
\boldsymbol{U}=\left[\begin{array}{c}
u_{\mathrm{p} \alpha} \\
u_{\mathrm{p} \beta} \\
u_{\mathrm{s} \alpha} \\
u_{\mathrm{s} \beta}
\end{array}\right] \quad \boldsymbol{I}=\left[\begin{array}{c}
i_{\mathrm{p} \alpha} \\
i_{\mathrm{p} \beta} \\
i_{\mathrm{s} \alpha} \\
i_{\mathrm{s} \beta}
\end{array}\right] \\
\boldsymbol{R}=\left[\begin{array}{llll}
R_{\mathrm{p}} & -\omega L_{\mathrm{p}} & 0 & -\omega L_{\mathrm{m}} \\
\omega L_{\mathrm{p}} & R_{\mathrm{p}} & -\omega L_{\mathrm{p}} & 0 \\
0 & -\omega L_{\mathrm{m}} & R_{\mathrm{s}} & -\omega L_{\mathrm{s}} \\
\omega L_{\mathrm{m}} & 0 & \omega L_{\mathrm{s}} & R_{\mathrm{s}}
\end{array}\right] \\
\boldsymbol{L}=\left[\begin{array}{cccc}
L_{\mathrm{p}} & 0 & L_{\mathrm{m}} & 0 \\
0 & L_{\mathrm{p}} & 0 & L_{\mathrm{m}} \\
L_{\mathrm{m}} & 0 & L_{\mathrm{s}} & 0 \\
0 & L_{\mathrm{m}} & 0 & L_{\mathrm{s}}
\end{array}\right]
\end{gathered}
$$

The model, in the state space form, was implemented into MATLAB and the differential equations were solved there. The resistances and leakage inductances were determined from short circuit tests, the values can be found in Appendix. Observe that the magnetising inductance value $L_{\mathrm{m}}$ varies strongly during these voltage disturbance simulations due to the flux density dependency of the relative permeability of the M300-50A material used in the transformer core.

\subsection{Saturation modelling}

To be able to model the saturation phenomena of the transformers, an open circuit test [14] with variable voltage supply was performed resulting in a variable $L_{\mathrm{m}}$ as a function of the magnetising current $i_{\mathrm{m}}$ that can be seen in Fig. 3 .

The curves of the magnetising inductance that can be observed in Fig. 3 were then fitted to a polynomial equation, resulting in two expressions of the magnetising current, different for each transformer, shown in the following equation

$$
L_{\mathrm{m}}= \begin{cases}k i_{\mathrm{m}} & \text { for } i_{\mathrm{m}}<i_{\mathrm{m}} \text { limit } \\ \frac{p}{i_{\mathrm{m}}+q} & \text { for } i_{\mathrm{m}} \geq i_{\mathrm{m}} \text { limit }\end{cases}
$$

where $k, p$ and $q$ are the fitted parameters presented in Table 1 .

For a low magnetising current, the value of $L_{\mathrm{m}}$ is the result of (14), that is when the derivative of the magnetising inductance with respect to the magnetising current is positive in Fig. 3. When the

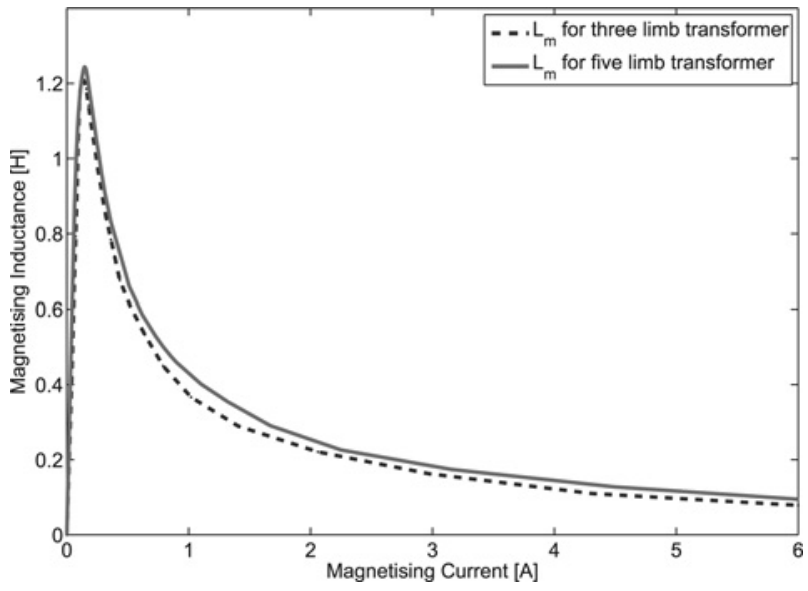

Fig. 3 Magnetising inductance, $L_{m}$, as a function of magnetising current $i_{m}$ for the two types of transformers during open circuit test with variable voltage 
Table 1 Parameters for modelling of $L_{\mathrm{m}}$

\begin{tabular}{lcccc}
\hline Type & $p$ & $q$ & $i_{m}$ limit & $k$ \\
\hline three limb & 0.4751 & 0.2405 & 0.13 & 9.13 \\
five limb & 0.5395 & 0.2754 & 0.1498 & 8.31 \\
\hline
\end{tabular}

magnetising current is above the peak of the magnetising inductance $\left(i_{\mathrm{m}}>i_{\mathrm{m}}\right.$ limit in Table 1$)$, the behaviour of $L_{\mathrm{m}}$ is determined by (15).

\subsection{Experimental setup}

Verifications of the simulation results were made in the laboratory setup presented in Fig. 4. An inverter with a DC generator supplying the DC-link, created a three-phase voltage that was applied across the transformer which in turn fed a load that could be changed to be lighter or heavier as well as inductive or resistive. In this way, any arbitrary voltage disturbance could be generated. Measurements of currents and voltages were taken before and after the transformer (MB \#1 and MB \#2) and fed into the real-time interface (RTI) d-SPACE in accordance with [15]. The voltage dips were implemented in MATLAB Simulink using look-up tables, and these were then converted to pulse-width modulation signals that were sent via the RTI to the opto sending and receiving card and then routed to the transistor control circuitry. To avoid the difference in behaviour due to the initiation of the voltage profiles [16], a zero crossing algorithm was implemented in the RTI to initiate the profiles at the same electrical conditions, each time a test was performed.

\subsection{Faulted steady-state operation}

The steady-state effect of voltage and frequency deviations on the two transformer types were investigated using a 'window test', that is, a table of frequency and voltage levels around the nominal values. The transformers were operated in open circuit and the voltage was varied between 0.5 and $1.5 \mathrm{pu}$, while the frequency was swept from

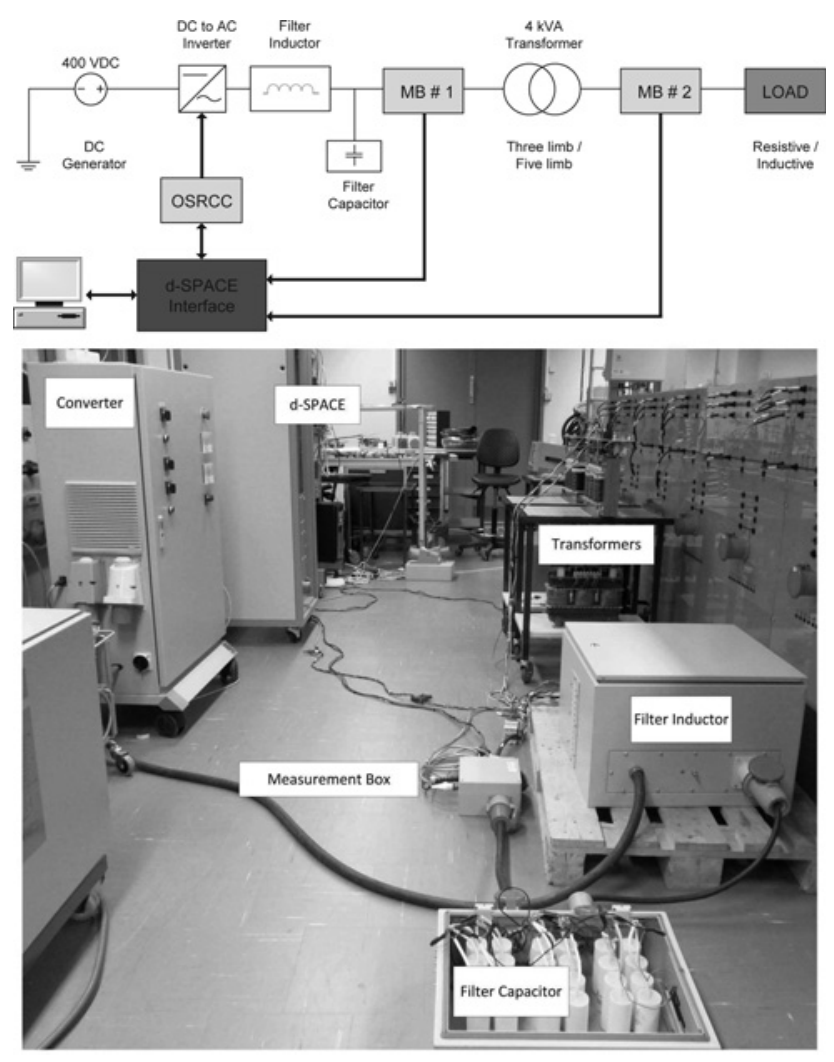

Fig. 4 Laboratory setup for practical validation of the model
45 to $55 \mathrm{~Hz}$. For simplicity and ease of comparison, nine points were chosen for which the results were evaluated. Thus at $50 \mathrm{~Hz}$, three readings corresponding to $0.5,1.0$ and $1.5 \mathrm{pu}$ voltage have been analysed. The same steps are repeated for 45 and $55 \mathrm{~Hz}$. The span of the variables was extracted from [1].

\subsection{Possible events on transformer}

Three dips were selected mimicking three disturbance cases that could occur on the power supply of an auxiliary system for a nuclear power station.

The first voltage profile (Fig. 5) is intended to simulate the loss of load (at rated power output, at $0 \mathrm{~s}$ ), followed by a transition to operation using an in-house turbine with a functional automatic voltage regulator (AVR). The profile is constructed based on the fact that the voltage drop over the sub-transient reactance is reduced to zero for a short period thus increasing the voltage to that of the back-emf of the generator. Through the use of the AVR the increased voltage is reduced within $1 \mathrm{~s}$ after a loss of load.

The second voltage profile (Fig. 6) represents the behaviour of the voltage during a load rejection while the main generator of the power plant is operating in the field current regulation (FCR) mode. The reason for this would be to manually operate the voltage at the terminal bus bar. As load is disconnected generator speeds up increasing back-emf further pushing voltage upwards. The time required until the voltage reaches a new stable voltage level is dependent on the parameters of the FCR, here however a level of $1.45 \mathrm{pu}$ is set as the maximum voltage. Since the flux is dependent on the $V / f$, this is expected to deeply saturate the transformers.

The third voltage profile (Fig. 7) shows the voltage on the auxiliary system bus (similar to the generator bus voltage), for a three-phase short circuit on the nearby $400 \mathrm{kV}$ bus. The generator keeps up the voltage at the auxiliary system to about $25 \%$ during the fault (fault levels indicated further in $[17,18]$ ). When the fault is cleared, after $100 \mathrm{~ms}$, the load is dropped and the unit turns into house-load operation, which is only a small fraction of the normal load. Therefore, the generator voltage goes quite high immediately

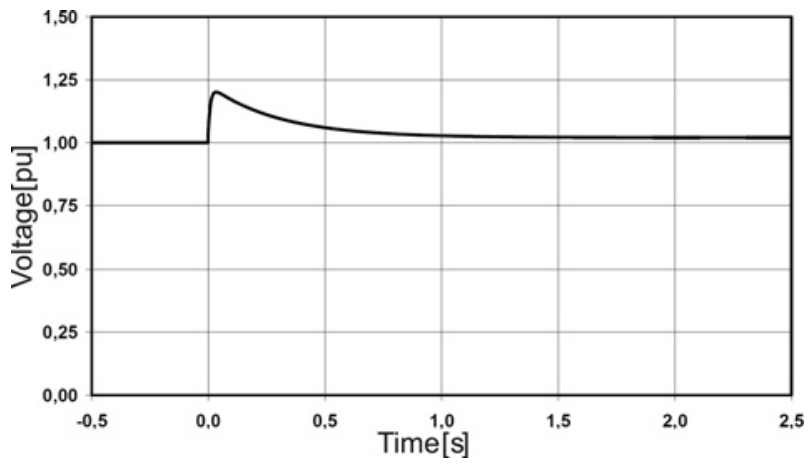

Fig. 5 Voltage profile 1: loss of load and transition to in-house turbine with proper regulation

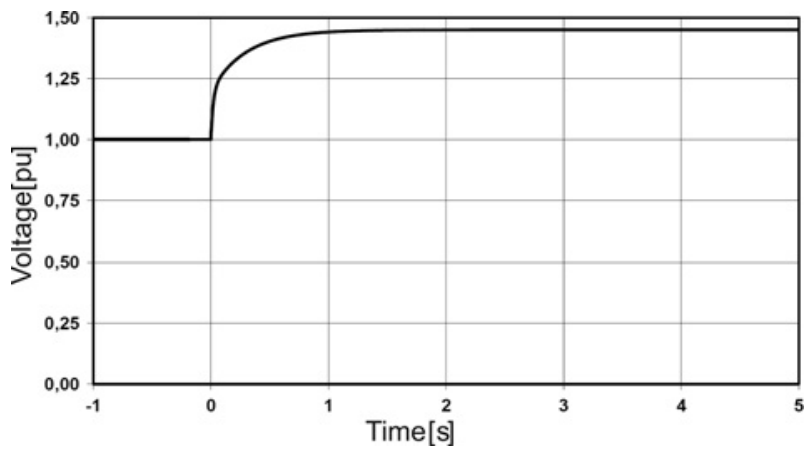

Fig. 6 Voltage profile 2: loss of load while using only FCR 


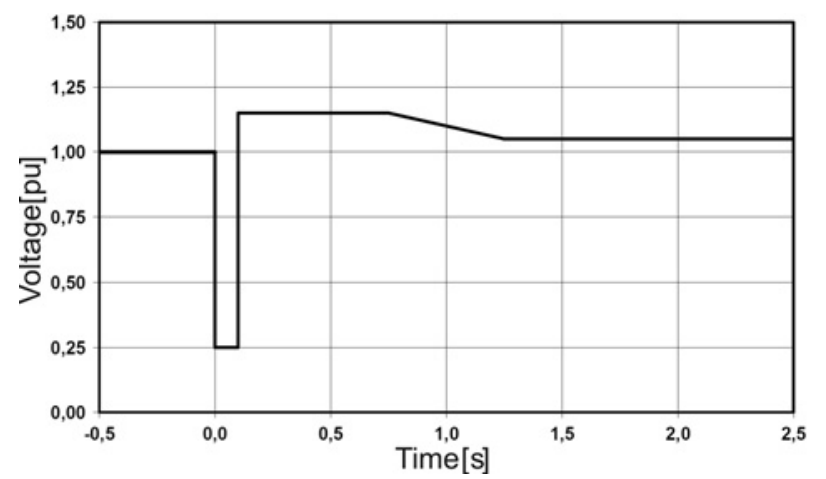

Fig. 7 Voltage profile 3: fault at bus bar and transition to in-house turbine with functional AVR

after the clearance of the fault. After less than a second the AVR of the generator has reduced the generator terminal voltage to a level slightly above $1 \mathrm{pu}$ in steady state.

\section{Results of the required steady-state operation}

Fig. 8 shows the measured results from the window test. It can be seen in the graph that there are nine sets of values. Each set consists of the open circuit currents of the three-limb transformer (left column) and the open circuit current of the five-limb transformer (right column) in pu. The first three sets are plotted for $45 \mathrm{~Hz}$ followed by $50 \mathrm{~Hz}$ and finally $55 \mathrm{~Hz}$. As expected, $45 \mathrm{~Hz}$ with 1.5 pu voltage is the worst case out of all the tests. Moreover, it can be seen that the three-limb transformer draws a higher current in open circuit as compared with the five-limb transformer. This higher current is due to the saturation of the core when increasing the flux in the limbs forcing the return flux from the top yoke of the transformer to the bottom yoke to travel through the high reluctance path of the air and surrounding area instead of the outer limbs for the five-limb transformer. Since the flux in each limb is proportional to $V / f$, this causes a $22 \%$ increase in flux in the case of $45 \mathrm{~Hz} / 1.5 \mathrm{pu}$ compared with that of the $55 \mathrm{~Hz} / 1.5 \mathrm{pu}$. When the core saturates, the seen magnetising impedance becomes smaller thus causing the increase in current.

\section{Results of the dynamic events}

In these tests, the voltage waveforms were always applied at the same time instant of the applied voltage, thanks to the RTI-controlled inverter, in order to ensure the same flux level in the transformers prior to the application of each voltage profile. The momentary values presented in the result figures are taken at the peak of the

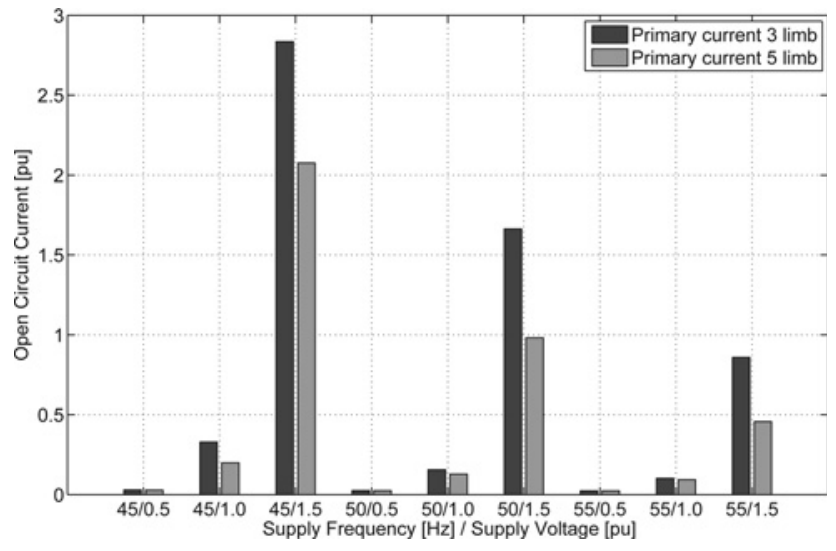

Fig. 8 Open circuit test for the two transformers with variable voltage and frequency swells in all voltage profiles. The quantities presented in this section are the primary side per unit currents, separated into active $(d)$ and reactive $(q)$ components of the currents. This is done by transforming the voltage vectors into a rotating coordinate system and then aligning the virtual grid flux vector with the $q$-axis.

\subsection{Voltage profile 1}

The first profile can be seen as a small disturbance and does not have much effect on the two types of transformers. This is true for both resistive and inductive loads at the secondary side. The load is either resistive (Fig. 9a) or inductive (Fig. 9b).

\subsection{Voltage profile 2}

Voltage profile 2 causes both transformers to saturate, causing an increase in the reactive current component. It is also clear that the inductive load increases the current demand even more, as compared with the resistive load.

From Fig. 10 it can be concluded that voltage profile 2 (Fig. 6) severely saturates both the transformers. Due to the unbalanced flux in the core during this saturated state, the three-limb transformer will draw a larger magnetising current. Compared with this, the outer limbs of the five-limb transformer provide a low reluctance path [19] for the unbalanced flux to pass through, which results in a lower magnetising current. If one considers the magnetising current in open circuit its current depends on the integral of the voltage across the winding. Thus, higher voltage as in profile number 2 will cause a higher maximum current during the evaluated profile window as compared with voltage profile 1 .
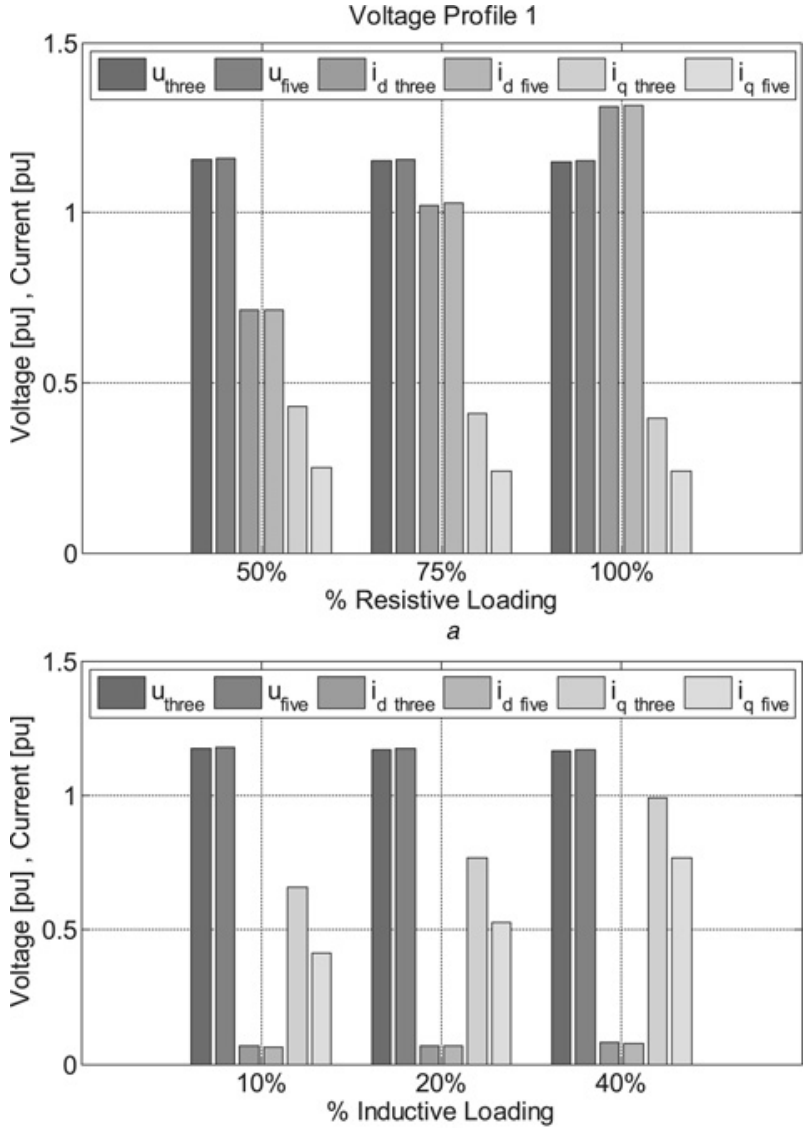

Fig. 9 Measured primary values of currents when voltage profile 1 is applied with

$a$ Resistive loading

$b$ Inductive loading

Results of both five- and three-limb transformers 

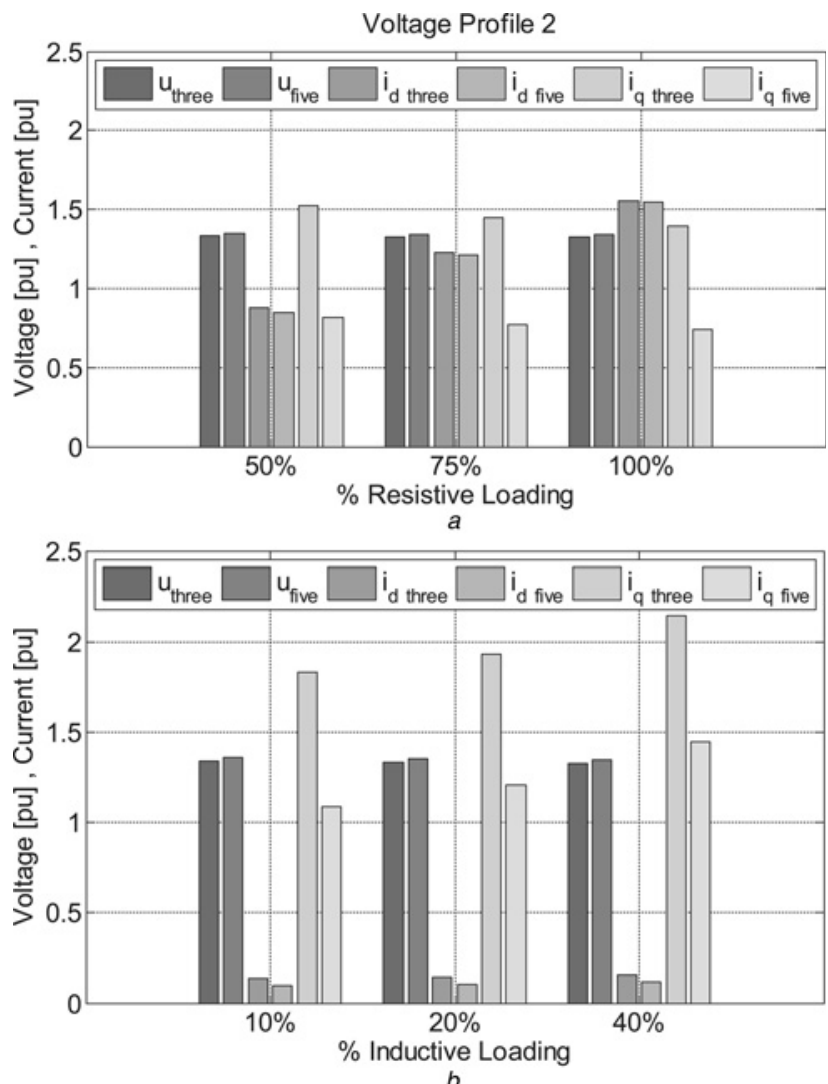

Fig. 10 Measured primary values of currents when voltage profile 2 is applied with

$a$ Resistive loading

$b$ Inductive loading

Results of both five- and three-limb transformers

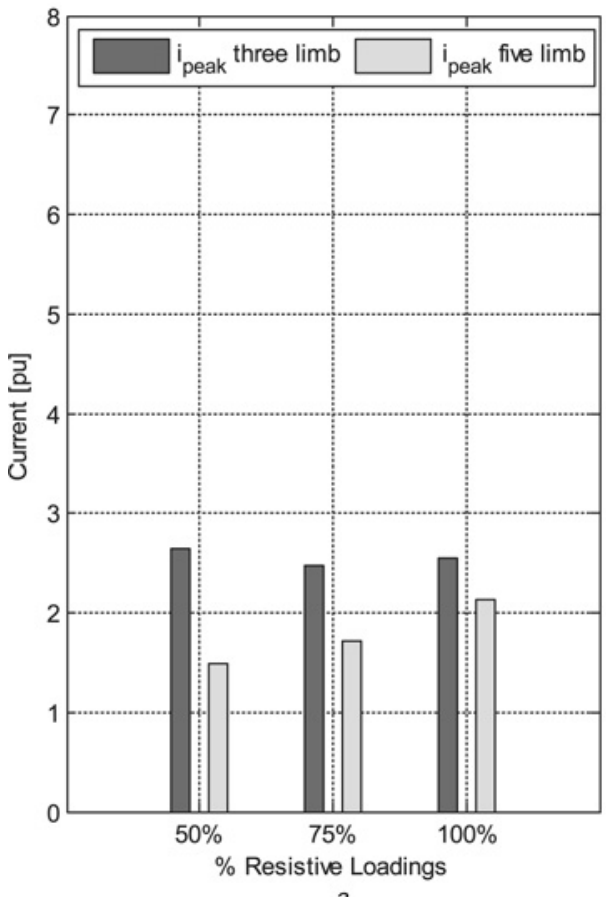

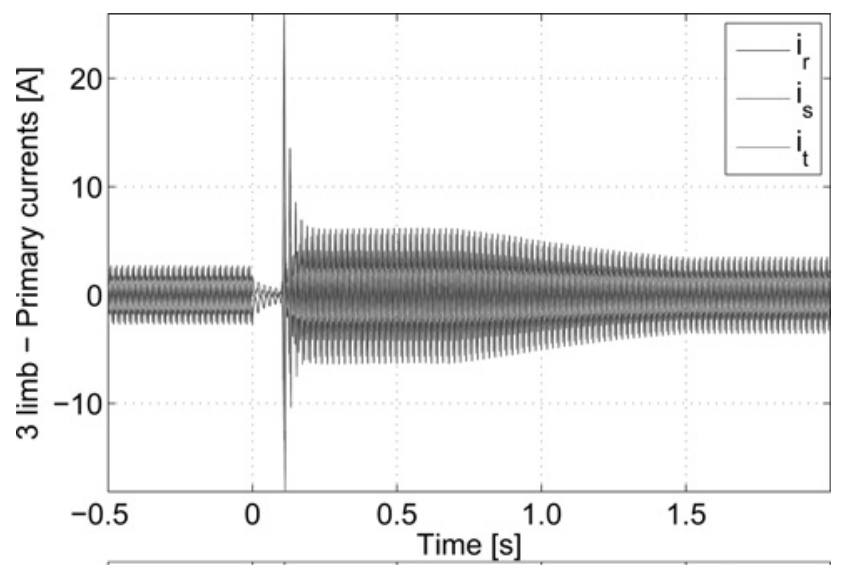

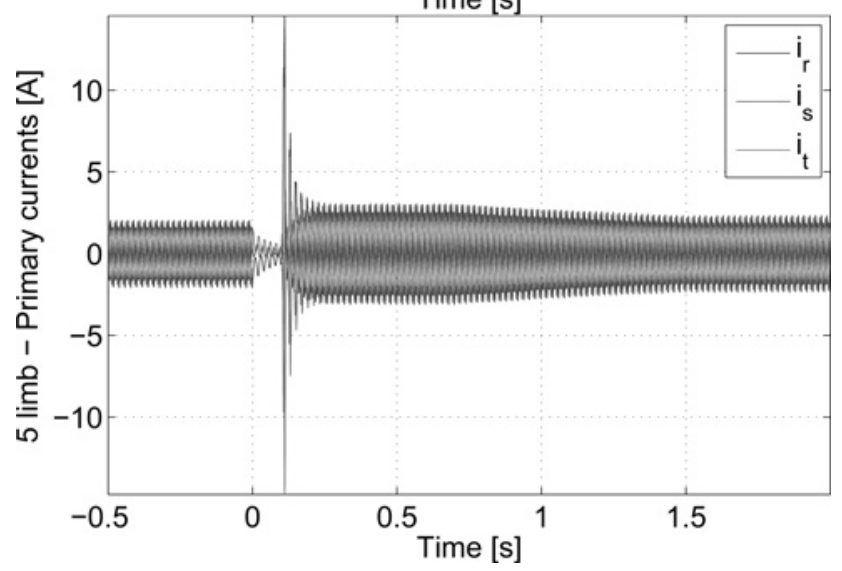

Fig. 11 Measured primary values of currents when voltage profile 3 is applied on three- and five-limb transformers with a $10 \%$ inductive loading

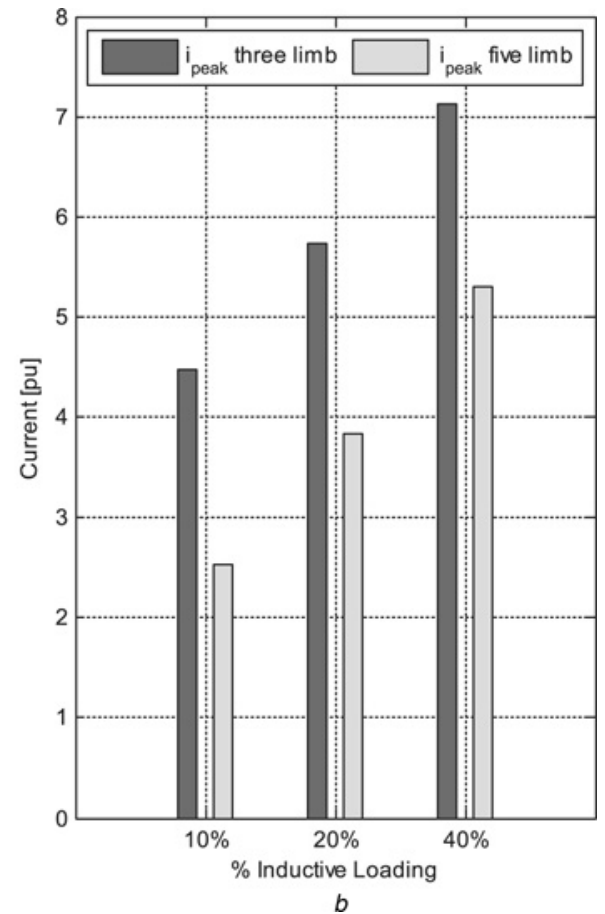

Fig. 12 Measured primary values of currents when voltage profile 3 is applied with

$a$ Resistive loading

$b$ Inductive loading

Results of both five- and three-limb transformers 


\subsection{Voltage profile 3}

Voltage profile 3 causes a large inrush current when the voltage recovers after the dip, and this saturate the two transformers very differently. It can be observed that the inductive load causes a larger inrush current due to the magnetising current of itself added to the saturation of the transformer. The time domain transient wave forms of the currents during an inductive loading of $10 \%$ are shown in Fig. 11 where a substantial difference can be seen in the primary side currents.

Another representation of the results from the different loading levels can be seen in Fig. 12.

Voltage profile 3 (Fig. 7) showed very interesting results that were related to the primary current drawn by the two types of transformers. A major difference between the inrush current drawn by the two types of transformers was observed when the voltage recovered after the dip. The amount of inrush current and behaviour of the transformers were very different depending on the type of loading. For the resistive loading case (Fig. 12a), the inrush current drawn by the three-limb transformer was almost constant for all three loading cases while for the five-limb transformer, the current drawn increased gradually with increasing load. Still, the current drawn by the five-limb transformer was lower than that of the three-limb transformer. In the case of inductive loadings (Fig. 12b), one can see that the re-magnetisation of the inductive load after the voltage dip greatly affects the transformers inrush current. For example, the three-limb transformer with the $50 \%$ resistive loading case draws a current peak of $2.6 \mathrm{pu}$ while for a similar inductive loading of $40 \%$ it
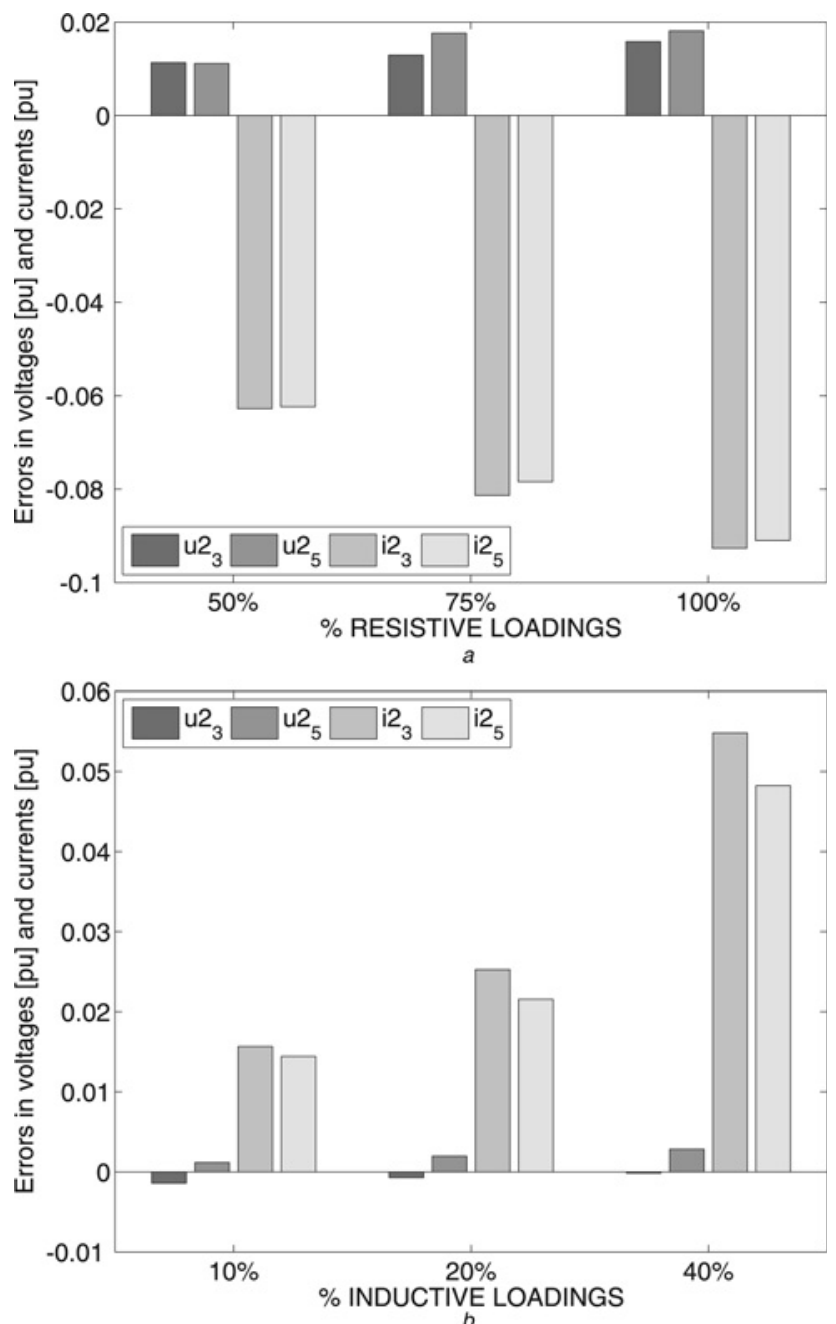

Fig. 13 Discrepancy between measured and modelled secondary voltages and currents for voltage profile 1 with resistive or inductive loadings. Results of both five- and three-limb transformers reaches a staggering $7.1 \mathrm{pu}$. This can be of an issue for the security of the grid [20].

\section{Comparisons between experiments and models}

In this section, a comparison between the error is shown between the values received from measurements and the simulated values from the models. In the comparison the secondary quantities are used. Since the load is purely resistive or purely inductive, only one discrepancy current component on the secondary side is presented. The discrepancy/errors $(\varepsilon)$ are taken in accordance with

$$
\varepsilon=X_{\text {meas }}-X_{\text {sim }}
$$

where $X_{\text {meas }}$ is the measured value (current or voltage) and $X_{\text {sim }}$ is the simulated value. The nomenclature of the plots are as follows, $u 2_{3}$ meaning the secondary voltage of the three-limb transformer. The error in the measured responses versus that of the modelled is presented in Figs. 13-15.

It can be concluded from Figs. 13-15 that the error is relatively small in all cases except for the difference in the current. This error is mainly due to the limitations in the real setup in the lab. This was due to the heating of the loads and the accuracy of the measured resistance and inductance which was performed during the initial stages of the test session. It can also be seen that the secondary voltage has a relatively small error compared with the error of the current.
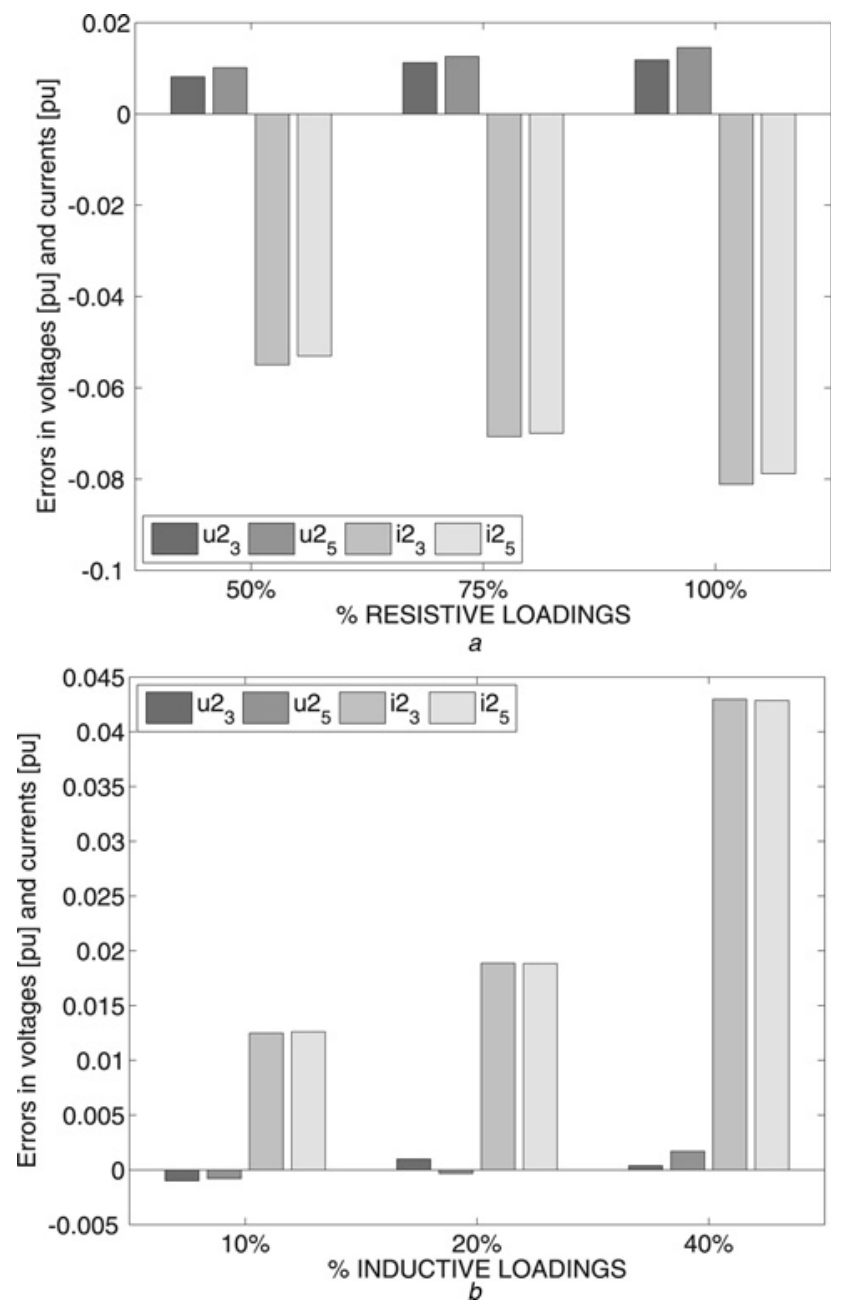

Fig. 14 Discrepancy between measured and modelled secondary voltages and currents for voltage profile 2 with resistive or inductive loadings. Results of both five- and three-limb transformers 


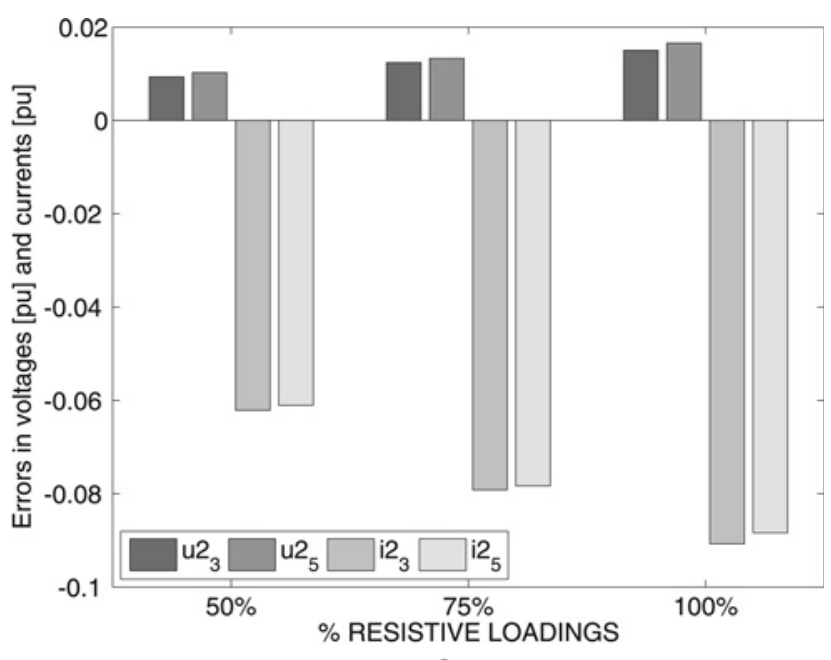

a

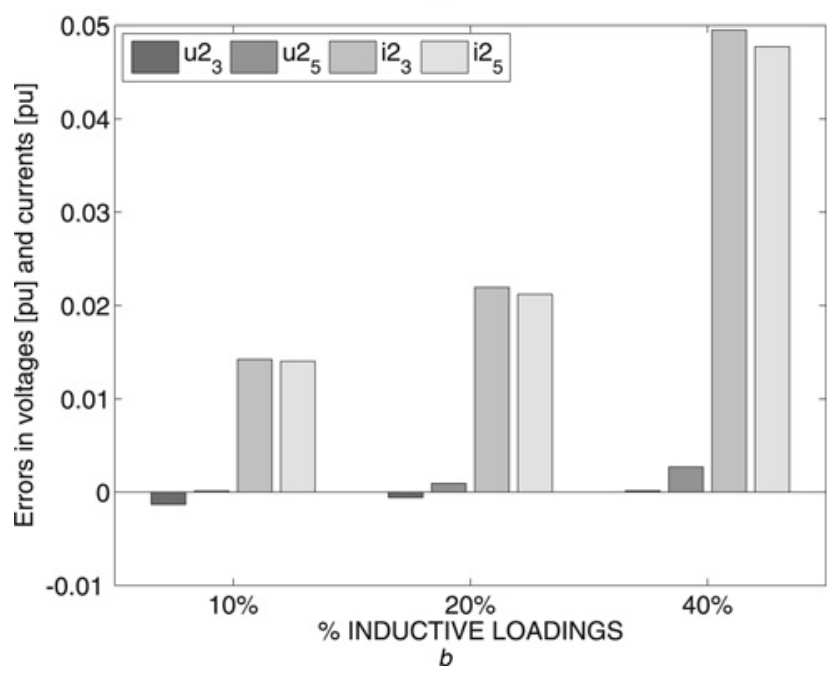

Fig. 15 Discrepancy between measured and modelled secondary voltages and currents for voltage profile 3 with resistive or inductive loadings. Results of both five- and three-limb transformers

\section{Conclusions}

A fifth-order Park model is derived to compare three-limb and five-limb transformers for both steady-state as well as transient conditions. The results of the simulation have also been verified on two $4 \mathrm{kVA}$ transformers. In steady-state operation, it is observed that a five-limb transformer gives lower primary currents as compared with the three-limb transformer, especially in the highly saturated region. One can comment that the current drawn by the two transformers in their saturated state differs severely depending on the topology of the core.

During the dynamic events, it is apparent that in both cases, that is, a voltage swell (voltage profile 2 ) and voltage recovery after the dip (voltage profile 3), the three-limb transformer draws more current as compared with the five-limb transformer mainly due to difference in reluctance path offered to the flux. Besides this, an inductive load contributes to a larger amount of current drawn as compared with a resistive load. It is thus demonstrated that the behaviour of different transformers not only depends on the core topology but also on the type and percentage of load being fed at the secondary side.

A final conclusion is that the simulation results are in good agreement with the measurements.

\section{Acknowledgments}

The financial support given by OKG AB is gratefully acknowledged. Moreover, the authors thank Bertil Svensson and Daniel Karlsson from Gothia Power, Electromagnetic Field Expert Eva Palmberg, Professor Per Norberg and Professor Massimo Bongiorno for interesting and developing discussions.

\section{References}

1 Duchac, A., Nöel, M.: 'Disturbances in the European nuclear power plant safety related electrical systems', J. Electr. Eng., 2011, 62, (3), pp. 173-180

2 Mork, B.A., Gonzalez, F., Ishchenko, D., et al.: 'Hybrid transformer model for transient simulation part i: development and parameters', IEEE Trans. Power Deliv., 2007, 22, (1), pp. 248-255

3 Mork, B.A., Gonzalez, F., Ishchenko, D., et al.: 'Hybrid transformer model for transient simulation part ii: laboratory measurements and benchmarking', IEEE Trans. Power Deliv., 2007, 22, (1), pp. 256-262

4 Ribbenfjärd, D.: 'Electromagnetic transformer modelling including the ferromagnetic core'

5 Arturi, C.: 'Transient simulation and analysis of a three-phase five-limb step-up transformer following an out of-phase synchronization', IEEE Trans. Power Deliv., 1991, 6, (1), pp. 196-207

6 Wang, J., Lascu, R.: 'Zero sequence circuit of three-legged core type transformers'. 62nd Annual Conf. for Protective Relay Engineers, 2009, 2009, pp. 188-213

7 Bhide, R., Kulkarni, S., Bhandarkar, P.: 'Analytical description for zero-sequence characteristics of five-legged core construction in transformers', IET Electr. Power Appl., 2010, 4, (6), pp. 407-417

8 Elleuch, M., Poloujadoff, M.: 'A contribution to the modeling of three phase transformers using reluctances', IEEE Trans. Magn., 1996, 32, (2), pp. 335-343, doi: $10.1109 / 20.486517$

9 Pedra, J., Sáinz, L., Corcoles, F., et al.: 'Symmetrical and unsymmetrical voltage sag effects on three-phase transformers', IEEE Trans. Power Deliv., 2005, 20, (2), pp. 1683-1691

10 Dolatian, M., Jalilian, A.: 'Voltage sag effect on three phase five leg transformers', Int. J. Electr. Electron. Eng., 2007, 1, (2), pp. 80-85

11 Kulkarni, S.V., Khaparde, S.: 'Transformer engineering: design, technology, and diagnostics' (CRC Press, 2012)

12 Chiesa, N., Lotfi, A., Høidalen, H.K., et al.: 'Five-leg transformer model for gic studies'

13 Persson, M., Baig, W.: 'Modeling and measurements of transformer behavior at different voltages and frequencies'

14 Johnson, D.W.: 'Egr 325, electromechanics technical paper $\sharp 2$ '

15 IEC, IEC 60688 - Electrical measuring transducers for converting ac electrical quantities to analogue or digital signals, 2002

16 Pedra, J., Sainz, L., Corcoles, F., et al.: 'Symmetrical and unsymmetrical voltage sag effects on three-phase transformers', IEEE Trans. Power Deliv., 2005, 20, (2), pp. 1683-1691, doi: 10.1109/TPWRD.2004.833910

17 Blackburn, J., Domin, T.: 'Protective relaying: principles and applications' (CRC Press, 2014, 4th edn.)

18 Styvaktakis, E., Bollen, M.: 'Signatures of voltage dips: transformer saturation and multistage dips', IEEE Trans. Power Deliv., 2003, 18, (1), pp. 265-270, doi: 10.1109/TPWRD.2002.804016

19 Tsili, M., Papathanassiou, S.: 'Analysis of a three-limb core power transformer under earth fault'. Proc. 16th Int. Conf. on Electrical Machines, 2004, pp. 1-6

20 Styvaktakis, E., Bollen, M.H.: 'Signatures of voltage dips: transformer saturation and multistage dips', IEEE Trans. Power Deliv., 2003, 18, (1), pp. 265-270

\section{Appendix}

See Tables 2-4.

Table 2 Measured parameters of transformer

\begin{tabular}{lcccc}
\hline Type & $R_{k}$ & $X_{k}$ & $R_{\mathrm{m}}$ & $L_{\mathrm{m}}$ rated, $\mathrm{H}$ \\
\hline three limb & 0.69 & 0.32 & 2235 & 0.37 \\
five limb & 0.61 & 0.2 & 3351 & 0.60 \\
\hline
\end{tabular}

Table 3 Result from open circuit test

\begin{tabular}{lccc}
\hline Type & $V_{\mathrm{p} n}, \mathrm{~V}$ & $I_{\mathrm{p},} \mathrm{A}$ & $P, \mathrm{~W}$ \\
\hline three limb & 118.60 & 1.02 & 79.0 \\
five limb & 114.48 & 0.62 & 44.9 \\
\hline
\end{tabular}

Table 4 Data on transformers

\begin{tabular}{lc}
\hline$A_{\text {core }}$ & $3.12 \times 10^{-3} \mathrm{~m}^{2}$ \\
\hline winding ratio $(N 1 / N 2)$ & $112 / 112$ \\
winding area & $2 \mathrm{~mm}^{2}$ \\
$U_{n}$ & $200 \mathrm{~V}$ \\
$I_{n}$ & $5.8 \mathrm{~A}$ \\
Mrtl. & $\mathrm{M} 300-50 \mathrm{~A}$ \\
\hline
\end{tabular}

